\title{
LIDAR STUDIES ON THE OPTICAL CHARACTERISTICS OF HIGH ALTITUDE CIRRUS CLOUDS AT A LOW LATITIUDE STATION, GADANKI $\left(13.5^{\circ} \mathrm{N}, \mathbf{7 9 . 2}^{0} \mathrm{E}\right)$ INDIA
}

\author{
Gloryselvan S Jayeshlal ${ }^{\text {a }}$, Malladi Satyanarayana ${ }^{* a, b}$, Gopinathannair.S Motty ${ }^{\text {a }}$, Reji k Dhaman ${ }^{\text {a }}$, Vasudevannair \\ Krishnakumar $^{\mathrm{b}}$, Vellara.P MahadevanPillai ${ }^{\mathrm{a}}$, Duggirala Ramakrisnarao ${ }^{\mathrm{c}}$, Pindlodi. Sudhakar ${ }^{\mathrm{c}}$ and Parapatla. kalavathi ${ }^{\mathrm{c}}$ \\ ${ }^{a}$ Department of Optoelectronics, University of Kerala, Karyavattom, Trivandrum-695 581, \\ Kerala, India. (jayeshlalgs, mottygs, rejikdhaman2007, vpmpillai9)@gmail.com \\ ${ }^{\mathrm{b}}$ St.Gregorios college, pulamon P.O, Kottarakara, Kollam-691 531, \\ Kerala, India. krishnakumar.vasudevannair@gmail.com \\ ${ }^{c}$ Geetanjali College of Engineering and Technology, Cheeryal, Keesara,Hyderabad-501 301, \\ Andhra Pradesh, India. (dramkrao, pillodisudhakar, kalavathimtech)@gmail.com
}

KEY WORDS: Lidar, Cirrus Clouds, Optical Depth, Lidar ratio, Depolarization.

\begin{abstract}
Light Detection and Ranging (LIDAR) which is analogous to Radio Detection And Ranging (RADAR), has become an important and unique technology for atmospheric research and applications. The technology is widely used for the remote sensing of the Earth's atmosphere, oceans, vegetation and the characteristics of Earth's topography. Remote sensing of atmosphere, for its structure, composition and dynamics, is one of the proven applications of the lidar systems. More importantly the lidar technique is applied for the study of clouds, aerosols and minor constituents in the atmosphere. It provides the information on the above with good spatial and temporal resolutions and accuracy. The high altitude cirrus clouds which play an important role in the Earth's radiative budget and global climate can be studied by using the LIDAR system. These clouds absorb long-wave outgoing radiation from Earth's surface while reflecting part of the incoming short-wave solar radiation. Lidar measurements are useful in deriving the altitude, top height, bottom height and the optical properties of cirrus clouds, which are essential in understanding the cloud-radiation effects. The optical depth, the effective lidar ratio and the depolarization of the clouds are also derived by inverting the lidar signals from the cirrus clouds. In this paper we present the results on the lidar derived optical and microphysical properties of the cirrus clouds at a tropical station Gadanki $\left(13.5^{0} \mathrm{~N}, 79.2^{\circ} \mathrm{E}\right)$ India during two year period from 2009 to210. The seasonal variations of the cloud properties during the observation period are presented and discussed with reference to earlier period.
\end{abstract}

*Corresponding author E-mail: -drsatyanarayana.malladi@gmail.com.

\section{INTRODUCTION}

The impact of cirrus clouds is very complex due to their influence on both incoming solar radiations and outgoing radiation from the Earth. The high altitude cirrus clouds absorb long-wave outgoing radiation from Earth's surface while reflecting short-wave incoming solar radiation and thereby altering the radiative budget of atmosphere. The radiative and optical properties of cirrus clouds often vary causing either warming or cooling of earth's atmosphere indifferent periods (Ramanathan and Collins, 1991). Also cirrus clouds play a key role in the physical and chemical properties of upper troposphere and lower stratosphere by regulating the upper tropospheric humidity. Cirrus cloud measurements at tropics are receiving much attention due to their role in Earth's radiation budget. The aerosols, water vapor and temperature in the troposphere and lower stratosphere together play a key role in the formation of cirrus and their properties. As such simultaneous study of aerosols, clouds along with meteorological parameters is important to understand the characteristics of the clouds during a typical monsoon period. Indian Ocean and the Indian sub-continent are the regions where cirrus occurrence is maximum particularly during the monsoon periods. Here we present the lidar derived optical and microphysical properties of the cirrus clouds at a tropical station Gadanki $\left(13.5^{\circ} \mathrm{N}, 79.2^{\circ} \mathrm{E}\right)$ India during the two year period in 2009-210. The seasonal variations of the cloud properties during the observation period are presented and discussed with reference to earlier period.

\section{Experimental Methods}

The experiments are carried out using the elastic backscatter lidar system operational on a regular basis at NARL Gadanki. The lidar transmitter employs an Nd:YAG laser, operating at $532 \mathrm{~nm}$, with an energy of $550 \mathrm{~mJ}$ per pulse(Model: Powerlite 8020: of Continuum, USA). The lidar system is aligned to make the complete overlapping between the transmitter and receiver at a height of about 4 $\mathrm{km}$, so as to avoid the intense backscattered signals from the low altitude clouds and aerosols.17 days of cirrus cloud observation data covering the winter, summer and monsoon periods are used for the investigations. Simultaneous data on temperature are taken from radiosonde experiments conducted at the station during the same period. The back scattered lidar signal received from the cirrus clouds by the lidar system is used to characterize the cirrus clouds. 


\section{Cloud Extinction and Backscattering Coefficient}

The cloud extinction coefficient may be obtained, in general by following the widely used Fernald and Klett, (F. G. Fernald et al., 1984; J. D. Klett et al., 1981) lidar inversion methods. A range independent lidar ratio (LR) is used in these techniques for deriving the extinction coefficients. The altitude dependent LR value was calculated from the method described in detail by Satyanarayana et al.2010. Making use of the lidar system constants and from the measured back scattered signal power the extinction coefficient of the clouds is determined by inverting the lidar signals as described by Fernald.The aerosol backscattering coefficient can be calculated using Fernald's algorithm (1984).

\section{Cloud Optical Depth}

Optical properties, which are essential in understanding cloud-radiation effects, can be derived from lidar observations. The optical depth $\left(\tau_{c}\right)$ and the two way transmittance $(\mathrm{T})$ of the cloud can be obtained from lidar data using the equations

$$
\tau_{\text {cirrus }}=\int_{h_{\text {base }}}^{h t_{o p}} \sigma(h) d r
$$

Where $\sigma(h)$ is the extinction within the cloud, which extends from cloud base ( $\mathrm{h}_{\text {base }}$ ) to cloud top $\left(\mathrm{h}_{\text {top }}\right)$. Based on optical depth cirrus clouds are classified into sub-visual $\tau_{c}$ $<0.03$ ), optically thin ( $\tau_{c}$ between 0.03 and 0.3 ) and thick or opaque $\left(\tau_{c}>0.3\right)$.

\section{Depolarisation Ratio (ס)}

The depolarisation measurements can provide insight into the distribution of ice and water within clouds and help in the investigation of cloud formation and dynamics. The lidar signals from $\mathrm{P}$ and $\mathrm{S}$ channels are processed separately and the depolarization factor $\delta(h)$ is estimated as

$$
\delta(h)=\frac{\beta_{s}(h)}{\beta_{p}(h)}
$$

Where $\beta_{s}(h)$ and $\beta_{p}(h)$ are the backscattering coefficients of $P$ ansd $S$ channels (SunilKumar.etal.,2003). The depolarisation ratio is a function of altitude of the cloud and the temperature, and humidity distribution within the cloud.

\section{RESULT AND DISCUSSION}

Two year Lidar data are used to understand the seasonal variations of cirrus clouds in three prominent seasons such as winter (December, January, and February), summer
(March, April, May) and monsoon (south-west and north-east). The percentage of occurrence of cirrus clouds as a function of altitude at the same station were reported earlier (Sunilkumar2003). The optical depth of cirrus clouds gives the information about the radiative behavior and determines whether the cloud causes greenhouse (warming) effect or albedo (cooling) effect (Tekano et.al., 1995). Another important parameter is Lidar ratio (LR). Its variations can reveal the physical parameters of the cloud particles such as phase, size, shape and orientation.

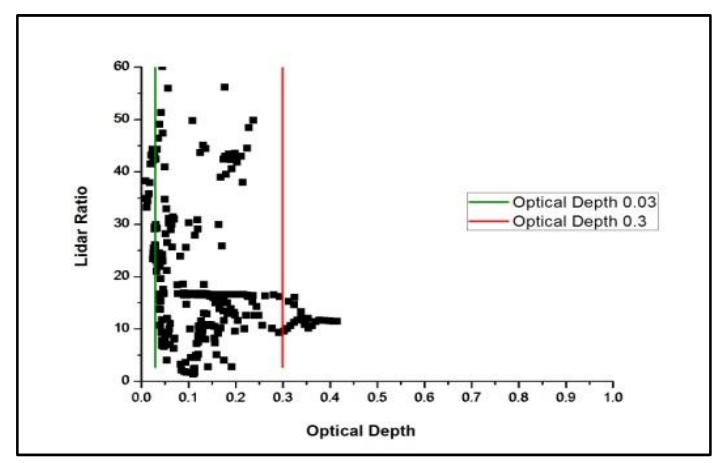

Figure.1: Lidar ratio and Optical depth relationship of cirrus clouds during 2009, 2010 winter season.

The optical depth values as a function of LR are shown in Fig1, Fig.2 and Fig.3 for the three seasons. The optical depth varied generally in the range between 0.038 and 1.2 with a high probability value between 0.1 and 0.2 . The probability of occurrence of cirrus with low values of $\tau_{c}$ was high and decreases with increasing $\tau_{c}$. The following division of cirrus based on the value of $\tau_{c}$ can be made from their visual appearance: $\tau_{c}<0.03$ for subvisual, $0.03<\tau_{c}<0.3$ for thin, and $0.3<\tau_{c}<3.0$ for opaque cirrus clouds (Sassen.et.al. 1992). It is noted that in about $50 \%$ of the cirrus observed days in all the three seasons together, the average value of $\tau_{c}$ was below 0.3 .

In winter season the upward convection and aerosol loading are very low resulting low optical depth and high LR values. From Fig. 1 it can be seen that even though the cirrus formed in winter is very thin they have large extinction values. This shows that the clouds are relatively of absorbing type and cause positive radiative forcing. The depolarization study shows that during winter the cloud composition consists ice crystals of predominantly horizontally oriented plates and columns.

From Fig. 2 it is noted that in the summer season the clouds are optically thick with relatively high optical depth values. 


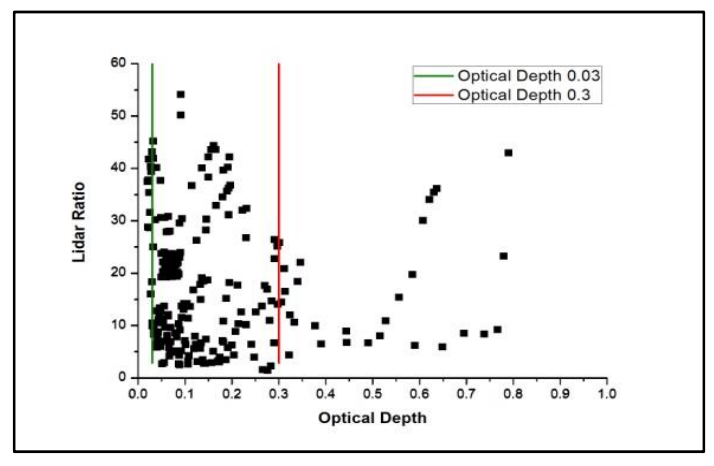

Figure.2: Lidar ratio and Optical depth relationship of cirrus clouds during 2009, 2010 summer season

Also it is clear that during summer season the LR values vary in a wide range and generally majority of the cirrus have LR values bellow 20 sr. For optically thin clouds during summer season the corresponding depolarization values also vary in a wide range from 0.1 to 0.5 in many cases. This can be attributed to the random orientation of the crystals present in the clouds due to the process of heterogeneous nucleation during summer period as suggested by DeMott.et al., ( 2010 )

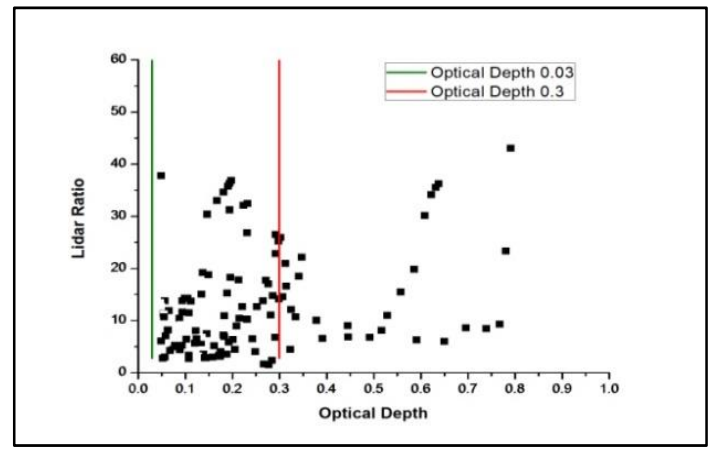

Figure.3: Lidar ratio and Optical depth relationship of cirrus clouds during 2009, 2010 Monsoon season

During monsoon period, as shown in the Fig. 3, the LR and depolarization values are very low and this indicates that the water content of the cloud is high even though the cloud temperature is low. The jet stream during monsoon period containing more oceanic aerosols could be one of the reasons for the high amount of water content during monsoon period (DeMott.et al., 2010). Because of large water content during monsoon period the altitude height of the cirrus is quite low making them potentially precipitating clouds.

\section{CONCLUSION}

Cirrus cloud seasonal LR and optical depth variations are studied and their relationship with depolarization values obtained in the same period is observed. Cloud optical depth is relatively high during the monsoon period. The seasonal differences in the optical depth may be due to probably the presence of particles of different sizes and varying composition of the cirrus clouds at this location.
This is to be further investigated. The cloud depolarization study indicates the possible crystal structure formed inside the cloud. Such information is valuable for validating and understanding the microphysical processes underlying the production and evolution of the ice particles.Presence of super cooled water present in the cirrus clouds affects the radiative budgeting. During monsoon season, the water content in the clouds is relatively high because of the available nuclei for condensation. Radiative budgeting of cirrus clouds depends on the phase, size and orientation of cloud particles

\section{Acknowledgments}

The authors would like to acknowledge National Atmospheric Research Laboratory (NARL) giving all data and support .One of the author Jayeshlal G S would like to acknowledge Department of Science and Technology for giving financial support under DST-PURSE program.

\section{REFERENCES}

1. B.A.Bodhaine, B.N.Wood, E.G.Dutton, and J.R.Slusser, (1999) "On Rayleigh optical depth calculations", J. Atmos. Ocean. Technol. 16, 18541861.

2. DeMott, P. J., A. J. Prenni, X. Liu, S. M. Kreidenweis, M. D. Petters, C. H. Twohy, M. S. Richardson,T. Eidhammer, D. C. Rogers(2010). "Predicting global atmospheric ice nuclei distributions and their impacts on climate".PNAS 107 (25) 11217-11222

3. F. G. Fernald, (1984). "Analysis of atmospheric lidar observations: some comments," Appl. Opt. 23, 652-653

4. Fletcher,N,H., "Active sites and ice crystal nucleation", J.Atmos.Sci.,1266-1278 (1969).

5. G. S. Jayeshlal, Malladi Satyanarayana, Reji K. Dhaman, and G. S. Motty Seasonal and optical characterisation of cirrus clouds over Indian subcontinent usingLIDAR AIP Conference Proceedings 1620, 179 (2014); http://dx.doi.org/10.1063/1.4898237

6. Hu, Y., (2007): "Depolarization ratio-effective lidar ratio relation: Theoretical basis for space lidarcloud phase discrimination", Geophys. Res. Lett., 34, L11812,

7. Satyanarayana,M,S.R.Radhakrishnan,S.Veerabhuthiran, V.P. MahadevanPillaiB.Presennakumar, V.S.Murty, and K.Raghunath (2010), "Laser radar characterization of atmospheric aerosols in the troposphere and stratosphere using range dependent lidarraio," J. Appl. Remote Sens., 4, 043503.

8. Sunilkumar, S. V. (2003), Lidar studies of high altitude tropical cirrus over Indian subcontinent, Ph.D. Thesis, University of Kerala, Trivandrum.

9. Takano Y., Liou K. N. 1995."Radiative transfer in cirrus clouds." Part III: Light scattering by irregular ice crystals. J. Atmos. Sci. 52, 818-837.

10. Sassen, K., and B.S.Cho (1992), "Subvisual thin cirrus lidar data set for satellite verification and climatological research,” J. Appl. Meteorol., 31, 12751285. 
11. Sunilkumar, S. V,K. Parameswaran, and B. V. Thampi (2008),"Interdependence of tropical cirrus properties and their variability", Ann. Geophys., 26, 413-429.

12. RadhakrishnanS.R (2011)"Studies OnLidar Inversion Methods And Characterization of Atmospheric Aerosols And Clouds At Low Latitude Tropical Stations" Ph.D. Thesis, University of Kerala, Trivandrum.

13.V. Ramanathan \& W. CollinsThermodynamicregulatin of ocean warming by cirrus clouds deduced from observations of the 1987 El Niño, Nature 351, 27 - 32 (02 May 1991); doi:10.1038/351027a0
14. Vasudevannair Krishnakumar, Malladi Satyanarayana, Soman R. Radhakrishnan, Reji K. Dhaman, Glory Selvan Jayeshlal, Gopinathan Nair S. Motty, Vellara P. Mahadevan Pillai, Karnam Raghunath, Madineni Venkat Ratnam, Duggirala Ramakrishna Rao, and Pindlodi Sudhakar Lidar investigations on the optical and dynamical properties of cirrus clouds in the upper troposphere and lower stratosphere regions at a tropical station, Gadanki, India $\left(13.5^{\circ} \mathrm{N}, 79.2^{\circ} \mathrm{E}\right)$, J. Appl. Remote Sens. 8(1) 083659 doi: $10.1117 / 1 . J R S .8 .083659$ 